\title{
Partnership approach: A good practice in teaching mental health
}

\author{
Joy Penman, Debra Papoulis, Kathryn Cronin \\ University of South Australia, Australia
}

Correspondence: Joy Penman. Address: University of South Australia, 111 Nicolson Avenue, Whyalla Norrie SA 5608, Australia. Telephone: 61-886-476-068. Email: joy.penman@unisa.edu.au.

Received: December 5, 2012

Accepted: March 14, $2013 \quad$ Online Published: May 9, 2013

DOI : $10.5430 /$ jnep.v3n12p47

URL: http://dx.doi.org/10.5430/jnep.v3n12p47

\begin{abstract}
Background/Objective: This paper examines the ternary relations that a Nursing Unit in a regional university campus in South Australia has created in delivering a mental health course to its first-year students studying in the Bachelor of Nursing program. The partnership may be described as three-cornered, where one corner would be the nursing students and the university represented by the academic teaching in the course, another would be the mental health clinicians, and the third corner would be the mental health care workplaces represented by the mental health nurses working with the students during placement. The outcomes of this three-way relationship on students' course experience and satisfaction is the focus of this paper.
\end{abstract}

Methods: The impact of the partnership in teaching a mental health course on eleven $(n=11)$ students was determined through a twelve-item questionnaire administered at the conclusion of the course. The questionnaire examined students' experience with the partnership approach, clinician-driven activities, best aspects of the course, impact on learning, and areas for improving future offerings. The collaborative initiative was also evaluated by an academic, three mental health clinicians and three mental health nurses using a modified one-minute questionnaire examining the most important outcome gained from the partnership, the best aspects of the partnership in delivering the course, areas to be included or expanded in the future, and personal and professional impact on university staff, clinicians and nurses.

Main findings: The majority of students found the conduct of the mental health course to be a pleasant learning experience. The inclusion of mental health clinicians provided many learning opportunities and afforded a better understanding of the role(s) of mental health nurses. Students felt positive about mental health nursing and some decided that they might pursue the speciality. The best things about the course from the students' perspective were being close to the reality of mental health practice, learning from real-life experiences, and the opportunity to put theory into practice in the mental health care workplaces. The best aspect of the partnership for the academic and clinicians was helping students better understand mental health issues by creating a real-life learning environment. For the mental health nurses in health care facilities, the best outcome was the opportunity to impart knowledge, broaden career paths, and demystify mental health.

Conclusions: This partnership between the university and industry in teaching mental health is a radical departure from traditional university formats. Findings from this pilot study showed an overall satisfaction with the partnership approach in teaching and learning mental health. The partnership was mutually beneficial; it was instrumental in bringing mental 
health to life, broadening career options for students and building human capacity. This is the start of an on-going academic and industry partnership which will provide the basis for future collaboration opportunities in education, research and clinical practice in a rural and regional setting.

\section{Key words}

Mental health, University-industry partnership, Mental health clinicians, Educational preparation of nurses

\section{Introduction}

One of the new courses offered in the revised nursing undergraduate curriculum of a South Australian university is Mental Health, a 4.5 unit course delivered on and off campus for first-year students. The aim of the course is to develop the knowledge, skills and attitudes to enable students to understand mental health issues besetting the population ${ }^{[1]}$. The course content includes contemporary topics such as: mental health and wellness across the lifespan, cultural and social construction of mental illness, mental state assessment, mental health illnesses, drug and non-drug interventions, recovery, evidence-based practice, and law and ethics. The course assessments consist of a mind mapping assignment, a mental state assessment, and a case study. The graduate qualities being developed in this course include sufficient body of knowledge, problem solving, ethical action and social responsibility.

The purpose of this paper is twofold: to describe the partnership model that was designed to effectively deliver the course Mental Health and to discuss student and staff reactions to some aspects of the course, specifically in relation to the collaborative teaching approach. The paper will first introduce inquiry-based learning which is the pedagogy underpinning the teaching of the course, and the course structure. This is followed by descriptions of the partnership, how it was formed and the structured tutorial activities showing the contributions of each partner. The instruments used to evaluate the initiative at the conclusion of the course are then explained and the findings analysed. The achievements of the initiative conclude the paper.

Catalysing the partnership is the on-going concern in nursing education delivered by tertiary institutions pertaining to the gap between what is being taught (theory) and what is actually happening in the workplace (practice). There are concerns not only about education and service, but, more recently, about practice and policy and the disparity between evidencebased practice and the realities of community practice. In response to some of these concerns, a collaboration between university and industry staff in the provision of undergraduate education was considered to be a strategy for overcoming the gap ${ }^{[2]}$. It was envisaged that a successful development and implementation of reality-based learning for students might be facilitated through such a partnership.

Accordingly, the academic staff of the Nursing Unit in a regional university campus partnered with staff of Country Health South Australia Local Health Network Mental Health Services (namely, a mental health knowledge broker, a senior mental health clinician, and a mental health nurse practitioner - all referred to as clinicians for purposes of brevity) and designated mental health care workplaces in order to deliver the course and provide clinical placements, respectively. In forming a ternary relationship ${ }^{[3]}$, as we did, all partners were able to work with each other, having a common purpose and keeping a focus on the primary task of teaching and preparing future nurses in the area of mental health.

This partnership initiative was undertaken not only to meet the objectives of the course, but to value-add by exposing students to mental health practice in rural and regional areas and providing opportunities for students to learn directly from on-the-ground mental health workers. The teaching arrangement featured an academic and three clinicians involved in the delivery of tutorials which ran for three hours a week for nine weeks during a study period. Also, students were given the opportunity to undertake clinical placements in various rural and regional mental health care facilities during the same study period. The partnership between the university and industry in teaching mental health is a radical departure from traditional university formats of lectures, tutorials and examinations. The new class format was piloted with a small class 
of nursing students studying in a regional university; findings from the evaluation would inform future implementation of the course.

\subsection{Structure of the course}

In structuring the Mental Health course, the pedagogy, delivery and resources are considered. The framework for teaching underlying the course is inquiry-based learning (IBL). In IBL, learning is organised around the student rather than subject content ${ }^{[4]}$. The rationale behind this approach to learning and teaching is to develop problem-solving skills and informal reasoning, as well as constantly seeking relevance and connections ${ }^{[4,5]}$. IBL falls under the constructivist approach characterised by collaboration, active engagement and personal relevance ${ }^{[6]}$, so pertinent for the course. It is premised on the belief that education begins with the curiosity of the learner ${ }^{[7,8]}$. Another feature of IBL is its emphasis on active engagement in the group process ${ }^{[9]}$. As such, it fosters student-student and student-staff interactions.

The course is delivered on and off campus for first-year students in the undergraduate nursing program. The class schedule for one semester includes three-hour tutorials for nine weeks and a two-week clinical placement (one week preparation and one week on site). Off-campus students navigate around the course website and are provided with online materials and support to help them engage with the content and peers. Learning is flexible; students learn at their own pace. Communication modes include face-to-face as well as through various information and communications technology such as email, phone, pod casts, virtual classroom and discussion groups. Note that this paper focuses only on the delivery of the course to on-campus students in a regional university campus.

The primary learning task is to develop the knowledge, skills and attitudes to understand contemporary mental health issues relevant to future nurses. The types of activities vary including Stripling's steps of inquiry - connecting to self, wondering and questioning, evaluating information, constructing new understandings, expressing new understandings and reflecting on one's own learning ${ }^{[5]}$. The predominant teaching methods for this course are tutorials that are facilitated by an academic and the clinicians, as well as computer-assisted teaching. A number of complex tasks need to be undertaken including readings, research and assessments. There is no final examination for this course.

The course is structured in such a way that students are required to undertake about ten hours of study per week. This covers lecture contact, reading and researching for assessments. The learning process for this single subject course is organised and delivered as other courses offered by our university. The main difference, however, is shared teaching with practising clinicians during tutorials and the opportunity for clinical placement in the area of mental health during the course.

\subsection{Partnership approach}

A partnership refers to two or more individuals embarking on a project for mutual benefit. Organisations and individuals initiate partnership arrangements where they agree to cooperate to meet goals and promote interests. However, for partnerships to work, the understanding of goals, expectations and outcomes associated with successful partnership is paramount. The primary characteristics of partnership success are commitment, coordination, and trust ${ }^{[10]}$. In addition, other attributes include efficient communication, active participation, effective conflict resolution technique and joint problem solving.

The university and industry partnership was formed in 2011 after a team of academics from the Nursing and Rural Health Unit of our university campus approached the mental health nurses of the Country Health South Australia (SA) Local Health Network Mental Health Services concerning a new course Mental Health that was being offered by the Unit in 2012. Country Health SA is a part of SA Health which oversees the rural health system in South Australia. Engaging with various sectors of society, including higher education, was a priority for Country Health SA in order to transform health care and ensure healthier lives of rural and remote South Australians. Following initial contact, several meetings were conducted with the purpose of clarifying the pedagogy, course objectives and structure, and the partnership model that was 
to be used as a framework to guide the university-industry relationship. The roles, expectations and benefits to be derived by the partners were discussed as well as the mechanisms by which the clinical placements for students might be organised.

A three-cornered partnership was formed, each corner representing a distinct human socio-spatial configuration allowing the flow of knowledge and experience between the partners. Mant ${ }^{[3]}$ called this a ternary relationship; one corner represented the nursing students and the academic staff teaching the course, another composed the mental health clinicians, and the third corner consisted of the nurses in mental health care workplaces. In clarifying the roles and contributions of each partner, it was agreed that the academic would provide the framework for teaching and sources of information, and articulate the requirements for students to pass the course. In a strong supportive role, the clinicians would share their expertise, provide authentic experiences and knowledge about various mental health topics. Finally, the practical input of mental health care workplaces through the mental health nurses would provide quality clinical placement opportunities for students during their one-week practical course.

Having determined the roles and responsibilities for each partner, the academic, clinicians and nurses involved clarified how each might mutually benefit from the relationship. Specifically from the academic's point of view, partnering with senior mental health clinicians could potentially yield advantages, for example, learning about contemporary clinical practice and mental health issues specifically relevant for rural and regional areas, and bringing a diversity of skills and experience in mental health into the classroom. From the clinicians' viewpoint, there is the opportunity to communicate their passion in this specialised area, reduce the stigma attached to mental illness, increase students' interest in mental health nursing, increase participation in mental health clinical placements, and increase student capacity to assess and care for consumers with mental health conditions. From the mental health care workplaces' perspective, the nurses specifically, there is the opportunity to showcase the services provided, increase interest in the mental health field, and entice students to work in the area.

\subsection{Structured tutorials}

Each week, students were provided with course topics online that they needed to work through before presenting to class. They were assigned readings and various activities to undertake individually or as a group. On the day of the tutorial class, they came together and shared their readings, findings and interpretations. Together, they constructed new understandings of the topic and discussed these new insights with their peers, academic and mental health clinicians.

Some de-identified real-life case scenarios were provided by the clinicians. A scenario typically reported on a consumer in the hospital or community setting experiencing a mental illness. The case scenario was complete with family history, signs and symptoms, investigations, treatments and interventions. Students attempted to make sense of the assessments conducted and understand the illness process in order to identify the consumer's nursing needs. They considered all human dimensions that might be impacted by the mental illness being experienced and determined appropriate nursing actions to care holistically for the consumer.

In the delivery of the tutorials, various teaching methods were employed. In addition to case scenarios, some other approaches were used, such as the "university street café" style, storytelling and open discussions which are more like rich conversations with experts talking and sharing their unique personal experiences. There were many opportunities for technology-assisted learning in the form of online readings and YouTube clips. Other clinician-driven interactive activities consisted of a "Hearing voices" workshop, "Mental state assessment of a woman with bipolar disorder", "Caring for the mind from an Aboriginal perspective", and many conversations with other mental health workers and community members who had experienced mental illness and were in recovery from their illnesses.

The tutorials that had been delivered mostly in a conversational tone, concluded with reflections on the learning that had taken place, and debriefing where students and staff clarified the learning that had transpired. The academic and clinicians 
conducting the IBL structured tutorials served as guides or mentors, rather than lecturers/teachers. They enhanced students' motivation by providing a cooperative and collaborative atmosphere ${ }^{[11]}$.

\subsection{Clinical placement}

Students experienced mental health nursing first hand and were afforded opportunities to apply theory into practice through the Experiential Learning Activities 1 (ELA 1) course. The course aims "to apply beginning level nursing knowledge and skills in a simulated practice environment and to explore the scope of practice of the Registered Nurse in a variety of community health care contexts" ${ }^{[12]}$. This placement provides beginning nursing students with an opportunity to explore different organisations, including mental health facilities, in order to appreciate how the organisations contribute to the health of individuals and populations in general. The mental health facilities, however, did not contribute in developing the course.

During the placement, students are expected to observe and communicate with clients and participate as a member of a team in the organisation. Some of the activities students may be involved in include: basic health assessments, documentation, development of a care plan for individuals and communities, development of communication strategies and critical reflection of learning, all at the beginning level. The academic and clinicians prepared the students for their clinical placement by helping them identify their objectives, clarifying expectations and learning outcomes, and honing nursing skills.

\section{Methods}

\subsection{Design}

A mixed method survey design was used to obtain qualitative and quantitative data concerning the perceptions of the course and the impact of the partnership approach on students' course experience and satisfaction. This methodology helps provide answers to the question "What is going on here?" as well as who, when, where, and how questions associated with a particular problem. This approach yields rich data that can lead to important recommendations ${ }^{[13]}$.

\subsection{Participants}

All eighteen students enrolled in the course were invited to participate in the survey. However, four students had withdrawn from the course. Of the fourteen students, eleven $(n=11)$ completed the questionnaire. One university staff member and three mental health clinicians were invited to complete the Harvard One-Minute Questionnaire. All $(\mathrm{n}=4)$ completed and returned the questionnaire. Nurses from the mental health care facilities $(n=3)$ were also approached for feedback.

\subsection{Data collection}

The impact of the partnership in teaching the mental health course on participating students was determined through a twelve-item questionnaire administered at the conclusion of the course. The anonymous questionnaire consisted of nine Likert-type questions, followed by three open-ended questions. Students were asked to indicate the extent of their agreement with statements describing their experiences. The questionnaire examined students' experience of the partnership approach, general perceptions of the course, clinician-driven activities, impact on learning, best aspects of the course, and areas for improvement.

The collaborative initiative was also evaluated by the academic staff member as well as the mental health clinicians and nurses. A modified Harvard One-Minute Questionnaire ${ }^{[14,15]}$ was used examining the most important outcome gained from the partnership, the best aspects of the partnership in delivering the course, areas to be included or expanded in the future, and personal and professional impact on university staff and clinicians. Participants were asked to complete this 
questionnaire at the conclusion of the course. This type of evaluation has high completion rates and is simple to prepare and administer, is relatively quick to execute, and is generally well received ${ }^{[14]}$. This tool is an ideal and effective learning technique in that it asks questions which stimulate reflection and critique of content immediately after the event ${ }^{[15]}$.

\subsection{Data analysis}

Descriptive and frequency analyses were performed; data analysis consisted of sorting the data into files and tables, and counting frequency of responses. The search for themes was accomplished by reducing the participants' statements and phrases in their description, observation and understanding to codes and themes.

\subsection{Ethical considerations}

A brief letter introducing the survey was distributed together with the questionnaire to the students during their class. The letter included the purpose of the study, participants' actual involvement, a statement regarding the voluntary nature of participation and assurance of confidentiality of information provided. Completing the questionnaire was taken as consenting to participate in the evaluation. In order to preserve students' anonymity and confidentiality, names were not required. A similar procedure was applied for the academic, clinicians’ and nurses’ survey.

\section{Findings}

\subsection{Students' perceptions of the course}

Eleven of the fourteen students completed the survey, representing a 79\% response rate. The majority of the students "agreed" to "strongly agreed" that the course provided a pleasant learning experience, many learning opportunities, a better understanding of mental health concepts, mental health assessment, mental illnesses, interventions and treatments, and the role/s of mental health nurses. The majority felt positive about mental health nursing. In fact, a good number planned to pursue mental health nursing after they graduated (see Table 1).

Table 1. Number and percentage of respondents reporting perceptions about the course

\begin{tabular}{|c|c|c|c|c|c|c|}
\hline Statement & Agree & Percentage & Strongly agree & Percentage & Others & Percentage \\
\hline Pleasant learning experience & 2 & $18 \%$ & 9 & $82 \%$ & & \\
\hline Many learning opportunities & 5 & $45 \%$ & 6 & $55 \%$ & & \\
\hline $\begin{array}{l}\text { Better understanding of } \\
\text { MH* concepts }\end{array}$ & 4 & $36 \%$ & 7 & $64 \%$ & & \\
\hline $\begin{array}{l}\text { Better understanding of } \\
\mathrm{MH}^{*} \text { assessment }\end{array}$ & 5 & $45 \%$ & 6 & $55 \%$ & & \\
\hline $\begin{array}{l}\text { Better understanding of } \\
\text { mental illnesses }\end{array}$ & 5 & $45 \%$ & 5 & $45 \%$ & Neutral - 1 & $9 \%$ \\
\hline $\begin{array}{l}\text { Better understanding of } \\
\text { interventions / treatments }\end{array}$ & 7 & $64 \%$ & 3 & $27 \%$ & Neutral - 1 & $9 \%$ \\
\hline $\begin{array}{l}\text { Understanding of role of } \\
\mathrm{MH}^{*} \text { nurses }\end{array}$ & 7 & $64 \%$ & 4 & $36 \%$ & & \\
\hline $\begin{array}{l}\text { Feel positive about } \mathrm{MH}^{*} \\
\text { nursing }\end{array}$ & 2 & $18 \%$ & 9 & $82 \%$ & & \\
\hline Might pursue $\mathrm{MH}^{*}$ nursing & 3 & $27 \%$ & 5 & $45 \%$ & $\begin{array}{l}\text { Neutral - } 2 \\
\text { Disagree - } 1 \text { (only } \\
\text { because I want to } \\
\text { pursue midwifery }\end{array}$ & $\begin{array}{l}18 \% \\
9 \%\end{array}$ \\
\hline
\end{tabular}

*MH stands for mental health 
In addition, the students conveyed a number of 'best things' about the course. The two most popular responses were having clinicians as part of the teaching team and having guest speakers with lived experiences share their realities with the students. The opportunity to put theory into practice via clinical placements was another popular response. Five students thought that there were no areas to improve on. The rest suggested inviting more guest speakers, more support for assessment tasks, more role-playing, and a longer time for some sections of the course. When asked for additional comments, the students took the opportunity to compliment the conduct of the course by commenting on how enjoyable it was, that it was a good course to learn, and that it was very informative and well presented.

\subsection{Staff and clinicians' perceptions of the course}

The academic and three clinicians completed the modified Harvard One-Minute questionnaire, representing a 100\% response rate. They believed they benefited from the partnership as gleaned from their responses on the most important outcome/s gained. In addition to improved opportunities for future partnerships between the university and industry and increased understanding of mental health for students, they identified a better knowledge of the university, curriculum, and state-of-the-art practice in mental health.

Helping students better understand mental health issues by creating a real-life learning environment was deemed the best aspect of the partnership. The involvement of clinicians helped bridge the gap between theory and practice. The participation of other mental health workers and community members, as well as the organisation of clinical placements for students, achieved the same effect. The academic and clinicians enumerated several other positive outcomes of the partnership (see Table 2).

Table 2. Best aspects of the partnership

\begin{tabular}{ll}
\hline Item & $\mathbf{N}^{*}$ \\
\hline Working with the students and sharing stories of how the theory can be put into practice in the real world & 4 \\
The opportunity to bring outside workers (peer-support workers, non-government workers and people with a & 3 \\
lived experience) & 3 \\
The opportunity to link our networks, including encouraging/organising clinical placements & 2 \\
Learning from each other & 2 \\
To see the growth, development and confidence of the students as the tutorials progressed & 2 \\
Dispelling some of the stigma that surrounds mental health and mental health nursing & 1 \\
Sharing the experience of coordinating the tutorials & 1 \\
Students were interactive and inquisitive which demonstrated a high level of interest in learning about mental & 1 \\
health. & 1 \\
The attendance in each tutorial was good, which indicated a high level of interest from the students. & 1 \\
Mental health nursing is now an option for students. & 1 \\
Increase in mental health literacy and awareness &
\end{tabular}

*Number of times item identified

When asked what areas of mental health could be included or expanded in the course, the academic and clinicians were unanimous that early intervention, prevention and mental health promotion should be a priority. This was followed by highlighting the role of the primary care practitioner and the doctor in caring for mental health consumers. The impact of the teaching partnership for the academic was increasing the quality of her teaching, while for the clinicians it was learning about academia and students' learning, and reflecting on their practice. Finally, the query on further comments elicited highly satisfactory observations from the academic and clinicians. This satisfaction emanated from the perceived positive 
impact on students, from feeling welcomed and valued and being a part of a "great team". The team was described as having a smooth reciprocal relationship, with members having something different to offer.

\subsection{Mental health nurses' perceptions of the clinical placement}

Three mental health nurses employed by two regional health facilities where some students undertook their placements agreed to participate in the survey. The most important outcome gained from the clinical placement was a new generation of students showing genuine interest in mental health nursing as manifest in the rapport they developed with clients and peers alike. Their interests included assessment, recovery, development of resilience and coping and enhancing the selfesteem of clients. The best aspects of providing clinical placements for students from the mental health nurses' perspective were sharing first-hand knowledge, broadening the career pathway of students and demystifying mental health. Opportunities to have more and longer mental health clinical placements were suggested. Impact on nurses varied from satisfaction with having students to mentor to satisfaction derived from interacting with students.

\subsection{Major themes identified}

Melding the impressions of students, academic and clinicians, as well as nurses has given rise to new understandings of what it is like to offer a course featuring the ternary relations created in the partnership. The significance of introducing learning strategies that not only present knowledge as traditional approaches do, but engage students meaningfully and encourage greater interaction, motivated the staff to continue developing strategies that boost learning, enhance interactivity, and achieve academic rigour. The partnership approach achieved much for the partners contributing to the positive learning and teaching experiences of students, academic and clinicians, and mental health nurses supervising the students during placement ${ }^{[16]}$.

Over ten (10) themes emerged from the data that was coded into categories in this pilot study but only four (4) themes are reported in this paper. The experience of participating in the course Mental Health illustrated the first theme, which was labelled "mutually beneficial". Embedded in the second theme was students being brought close to the reality of mental health practice and the opportunity to put theory into practice in mental health workplaces, which was termed "bringing mental health to life". The third theme relates to students coming to terms with earlier stigma and misconceptions attached to mental health and now accepting it as a feasible career option following graduation. This is described as 'broadening career options". The fourth theme that emerged is the significant impact of the partnership on students' learning which was termed "building capacity". The discussion that follows illuminates these major themes.

\section{Discussion}

\section{“Mutually beneficial”}

The partnership approach in delivering the course was beneficial to the students for various reasons. The approach achieved a high level of interaction and engagement for the students who were encouraged to read and work through the course material and interact with clinicians who affirmed and challenged their beliefs and understanding and who provided them with different perspectives. The students were constantly encouraged to seek relevance and connections within their own realities. Also, students felt more supported in their study. In this partnership arrangement, knowledge is contextualised, interpreted and made more meaningful for students. Students remarked:

"Having mental health clinicians guiding and sharing their experiences with us is the best aspect of this course. I gained more insight and better understanding of mental health concepts.” (Nursing student 1)

"Very beneficial for my learning. I learnt how to deal with consumers with mental illness, empower them to work towards well-being and learnt to manage my own mental health as well." (Nursing student 2) 
“There is more support in the study, more interaction, more insight gained." (Nursing student 3)

The clinical placements, foundational in our nursing program, provided opportunities for students to learn experientially ${ }^{[17]}$. Real-life experience is valuable, there is immense learning that happens in this space and place and each experience is unique, but interrelated with other learning episodes. Providing opportunities to work in mental health facilities and immersing students in problem-rich environments helped hone their thinking and facilitate clinical knowledge acquisition, and enhance problem-solving and self-correction. The following quote summarises this sentiment from students:

"The best thing about this course is having the opportunity to observe and put in practice aspects of our mental health theory component. After learning about mental conditions, assessments, therapeutic relations, treatments and management in class, you get to see and experience these being played out in the clinic or home visits during the placement. Learning is more meaningful this way." (Nursing student 3)

The mental health nurses benefitted from the students who "were very eager to learn, enthusiastic and indicated that they wanted to do mental health when they finished their training. It was pleasing to see the younger generation taking an interest in mental health and for clinicians to pass on knowledge.” This experience encouraged them, affirmed their work, provided the nurses with "fresh eyes" on how to view their jobs, and helped them develop as clinical facilitators.

While the majority of students felt they had benefitted, the academic and clinicians conducting the tutorials expressed a similar positive appraisal of the course. The benefits emanated from being a part of a team and being able to inspire the students to pursue this area of specialty as they shared their passion and satisfaction in their work. Developing a relationship with students was important, as well as communicating ideal and appropriate professional values and attitudes to students. They (the academic and clinicians) served not only as mentors but also as role models, inculcating ethical action and social responsibility.

"I found this experience extremely exciting, we are a great team ... A very enjoyable experience, I looked forward to each week. We showcased Mental Health Nursing as a career option and enhanced people's mental health literacy." (Clinician 1)

"It was enjoyable to be able to participate in this new venture. I believe that if we are able to grow this partnership over the coming years it will help to demystify mental health in mainstream nursing as well as enticing nurses into the mental health specialty.... which will also improve recruitment and retention of health professionals in rural communities." (Clinician 2)

"Really enjoyed being with the students, developing a relationship with them, their trust in us with sharing their personal stories \& conversations. I was impressed that students continued to come to (non-compulsory) 9 am tutorials including 4 who lived out of Whyalla." (Clinician 3)

"Students will come to realise the significance of this field of study through the lens of experts and experience vicariously the tremendous satisfaction of helping people with complex mental health issues.... I am thrilled with the outcomes of this course which includes personal and professional benefits." (University academic)

Further, the academic and clinicians reported that they learnt from each other. The staff member felt that the collaboration increased the quality of course delivery, and felt that her own clinical skills had improved. While she was knowledgeable about the topics and she understood students well, she was not immersed in the workplace environment in comparison with the clinicians. The clinicians on the other hand learnt about academe, teaching and learning styles, and developed insights into teaching and coordinating tutorials. Encouraged by the academic's and students' attitude and interest, they 
were also challenged to think about their individual practice, reflecting on what motivates their particular thinking and how they might continue improving their practice.

\section{"Bringing mental health to life"}

Mental health coming to life is encapsulated in the second theme. The authentic partnership approach enhanced learning because it originated from the practical experiences of experts thereby narrowing the gap between theory and practice. Students gained an understanding of the current workplace environment, which would better prepare them for future practice. They gained insights into the many dimensions of practice and possible alternatives in caring for mentally ill consumers as they observed and discovered how clinicians think and behave. The stories told were effective ways of getting important points across. The real-life learning environment that was presented helped focus and engage students with the realities of practice in the world as it is.

This interface with clinicians was further enhanced by the involvement of community members who had almost become 'experts' on their condition/s. The use of 'experts' is well documented, offering advantages such as possessing extensive prior knowledge and knowledge of real world practice situations, as well as organising knowledge according to deeper concepts ${ }^{[18]}$ from which students can learn. Hence, the students explored the experience of having a mental illness with the 'experts', assessed resources available and sounded possible interventions to implement thereby achieved a better understanding of the roles of mental health nurses.

Consider some of the students’ comments about the clinician-driven tutorials:

"The experience is extremely good and enjoyable. I learn a lot. It affords me a 'realistic' window of what goes on in a mental health service." (Nursing student 4)

"Very enlightening learning different stories. The discussions were enriched and valuable. They broadened my view. I was able to witness how mental health experts think, rationalise, behave and solve problems." (Nursing student 5)

\section{“Broadening careers options"}

Theme three relates to broadening career horizons for the students. Though mental health nursing is a challenging profession, understanding its scope seems to focus on mental illness. With mental illness, however, comes the stigma, creating confusion, discrimination, prejudice and even fear ${ }^{[19]}$. Stigma results in alienation from support systems, social isolation and negative health outcomes. It is paramount to address the stigma attached to mental illness because it leads to many myths, misconceptions and inaccuracies that are not productive for the clients, their families as health care professionals.

Undeniably, our students' initial attitude and behaviour was negative, but this was because knowledge and experience were limited and they were not exempt from prevailing societal misconceptions. However, because of the partnership model, the topic of stigma was addressed exhaustively resulting in some students deciding to pursue a mental health career after graduation. The evaluation showed that the majority of the students felt positive about mental health nursing. Accordingly, several were determined to consider this field of specialty in the future. The clinicians and nurses were convinced that students came to realise that mental health nursing could be a "fulfilling and interesting career path" and was not "all bad and scary".

A mental health nurse wrote as one of the best aspects of the placement:

"The students enjoyed going on home visits, sitting in on allocation and assessments, learning from senior staff and learning how the team works ... in immersing students we possibly influenced them to seriously consider mental health as a career pathway in the future." 


\section{“Capacity building"}

Of the many current resources provided for the course, the involvement of clinicians and nurses as a human resource is valuable and innovative. This has resulted in many learning opportunities for the students that facilitated building capacity in the area of mental health at a basic level. Learning focused on the areas of understanding various mental health concepts, the mental state assessment tool, various mental illnesses, and current available interventions and treatments. The partnership approach promoted the transfer of knowledge and expertise across students, academic and clinician partners. This flow translated into local capacity building. Clinician 2 supported this belief, stating that:

"This is an exciting opportunity to build relationships and working relationships between industry, learning and academia, to assist students, nursing in this case, transfer knowledge into practice. ...most important for capacity building."

There were opportunities to develop and practise various skills, such as mental health assessment, communication, team work, problem-solving and behaviour management. The widening of students' views and understanding of mental health as well as the extension of teaching, clinical skills, team work and coordination for the academic/clinicians were but a few of the identified benefits of the partnership. In addition, the academic and clinicians assumed facilitator roles during the tutorials, assisting students to be actively involved in the group process. They guided students in using a variety of questioning strategies, helped them develop clinical reasoning skills, and encouraged them to connect with their own experiences.

The following anecdotal remarks illustrate further capacity building:

"Students learnt the recovery journey and the lived experience, inspiring them and providing rich tutorials that would be invaluable to them as they prepare to embark on their careers." (Clinician 3)

"They [the clinicians] demonstrated to the students how they solved problems and made decisions, increasing students' interest at the same time." (University academic)

The clinical placements helped build capacity by allowing the students to experience what it is like to be a mental health nurse, even for a short while. The placement provided the opportunity to experience conversing and being with clients, focusing on clients' experiences and engaging first hand with clients, filtering relevant from irrelevant information, and thinking of means and alternatives to help them.

Through our partnership involvement, course delivery and support were mobilised for students. The impact of knowledge, skills and strategic partnerships influenced the educational outcomes of the course. The data generated from our initiative affirms the positive impact of our partnership on capacity building among students.

\section{Future directions}

Areas for improvement were identified and the academic and clinicians will endeavour to explore further a variety of teaching methods including role playing and more guest speakers. It is imperative that there is more careful planning for the tutorials. Another future direction is the inclusion of mental health in higher year levels of the nursing program and the availability of longer mental health care placements for students. This is the start of an on-going academic and industry partnership which will provide the basis for future collaboration opportunities in education, research and clinical practice in a rural and regional setting. 


\section{Conclusion}

Findings from this pilot class evaluation and reflections of the academic and clinicians show satisfactory outcomes from the partnership approach in teaching and learning. It is so important that, in the educational preparation of nurses, they see concretely the connections between the university, clinicians, health services and workplaces, and community. Our partnership approach accomplished these connections and more. The ternary relationship has increased communication possibilities which have led to enhanced student and staff teaching and learning experiences. This has created a new environment that is accessible to students, allowing the building of links and networks, exploring and developing new ones, and extending and expanding teaching and learning spaces and places. This is the start of an on-going academic and industry partnership which will provide the basis for future collaboration.

The overall desirable learning outcomes achieved so far can only be attributed to the authentic partnership thus created, and this partnership must be sustained. The aspects of the partnership that were helpful included: having clear goals, flexibility in pursuing them, cohesive strategies and actions, mutual respect, recognition of capacities, active and equal participation, mutual trust and benefit, and meeting of needs and expectations. Following Jones and Wells' description ${ }^{[20]}$ of what community engagement is, finding a "win-win" formula and sharing in its planning and implementation are crucial for future successful partnerships.

\section{References}

[1] University of South Australia. Course outline - Mental Health, HLTH 1037. Adelaide: Author; 2012 [cited 2012 July 17]. Available from: http://learn.unisa.edu.au/course/view.php?id=57789

[2] Gassner L-A, Wotton K, Clare J, Hofmeyer A, Buckman J. Theory meets practice. Collegian: Journal of the Royal College of Nursing Australia. 1999; 6(3): 14-28.

[3] Mant A. Identifying and developing leadership capabilities. Seminar Series July, No. 35; 1994; Melbourne: Incorporated Association of Registered Teachers of Victoria (IARTV).

[4] Duffy M, Cunningham DJ. Constructivism: Implications for the design and delivery of instruction. 2001; [cited 2011 September 15]. Available from: http://www.aect.org/intranet/publications/edtech/07/index.html

[5] Stripling BK. Inquiry-based learning. Stripling BK, Westport SHH, editors. Curriculum connections through the library (Principles and practice). Connecticut: Libraries Unlimited; 2003.

[6] Savery J, Duffy T. Problem-based learning: An instructional model and its constructivist framework. Wilson B, editor. Constructivist learning environments: Case studies in instructional design. New Jersey: Educational Technology Publications, 1996. http://dx.doi.org/10.1016/S1322-7696(08)60337-6

[7] Savery JR. Overview of problem-based learning: Definitions and distinctions. The Interdisciplinary Journal of Problem-based Learning. 2006; 1(1): 9-20.

[8] Bebb H, Pittam G. Inquiry-based learning as a 'whole-curriculum approach': The experiences of first-year nursing students. Learning in Health and Social Care. 2004; 3(3): 141-153. http://dx.doi.org/10.1111/j.1473-6861.2004.00071.x

[9] Cleverly D. Implementing inquiry-based learning in nursing. London: Routledge, Taylor and Francis Group; 2003.

[10] Mohr J, Spekman R. Characteristics of partnership success: Partnership attributes, communication behavior, and conflict resolution techniques. Strategic Management Journal. 1994; 15(2): 135-152. http://dx.doi.org/10.1002/smj.4250150205

[11] Cleverly D. Inquiry-based learning: Facilitators' perceptions of their effectiveness in the tutorial process. International Journal of Nursing Studies. 2003; 40(8): 829-841. http://dx.doi.org/10.1016/S0020-7489(03)00076-2

[12] University of South Australia. Course outline - Experiential Learning Acitivity: Foundation Practicum 1 (NURS 1055). Adelaide: Author, 2013 [cited 201314 February]. Available from: http://programs.unisa.edu.au/public/pcms/course.aspx?pageid=106000

[13] University of Southern California Libraries. Types of research designs. California: Author; nd [cited 2012 November 26]. Available from: http://libguides.usc.edu/content.php?pid=83009\&sid=818072

[14] Stead D. A review of the one-minute paper. Active Learning in Higher Education. 2005; 6(2): 118-131. http://dx.doi.org/10.1177/1469787405054237

[15] Drummond G. Programme feedback; it only takes a minute? International Journal of Educational Management. 2007; 21(1): 29-36. http://dx.doi.org/10.1108/09513540710716803 
[16] Penman J, Cronin K, Martinez L, Papoulis D, White F. Caring for your own mental health and for others' mental health: A partnership approach. Proceedings of the 13th International Mental Health Conference: Positive change investing in mental health; 2012 August 6-8; Outrigger, Surfers Paradise, Australia. AST Management Pty Ltd: Queensland; 2012.

[17] Penman J, Oliver M. Meeting the challenges of assessing clinical placement venues in a Bachelor of Nursing program. Journal of University Teaching and Learning Practice. 2004; 1(2): 59-73.

[18] Horii CV. Teaching insights from Adult Learning Theory. Journal of Veterinary Medical Education. 2007; 34(4): 369-376. PMid:18287460 http://dx.doi.org/10.3138/jvme.34.4.369

[19] Gorman D, Cross W.Cultural issues in mental health. In: K-l Edward, I Munro, A Robins, A Welch (Eds). Mental health nursing: Dimensions of praxis. South Melbourne, Victoria: Oxford University Press. 2011: 427-442.

[20] Jones L, Wells K. Strategies for academic and clinician engagement in community-participatory partnered research. Journal of American Medical Association. 2007; 297(4): 407-410. http://dx.doi.org/10.1001/jama.297.4.407. 